Historic, Archive Document

Do not assume content reflects current scientific knowledge, policies, or practices. 

ᄃX J E A R Y

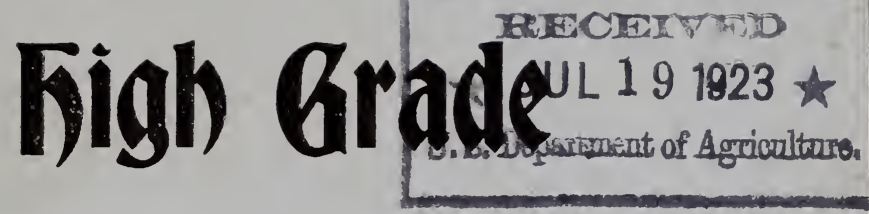

comato

seeds

0.000909000

I90I

Crop

W. H. BARRETT,

ADRIAN, MICH.

:2xies. 


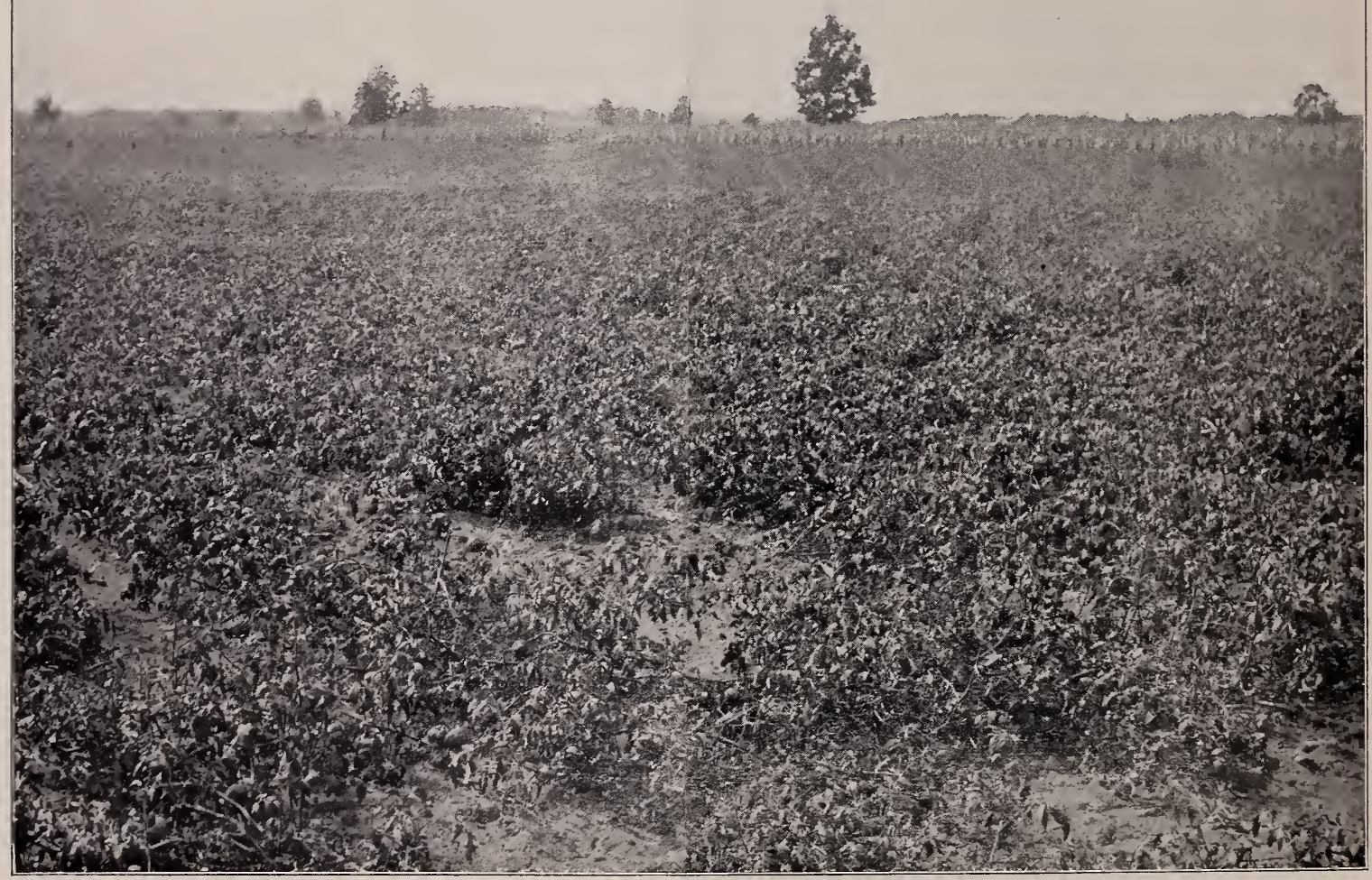

TWENTY ACRES OF STONE TOMATOES. 
$\therefore$ "None Better, Few as Good." ¿c

\section{HIGH GRADE}

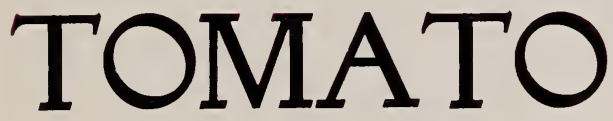

SEEDS
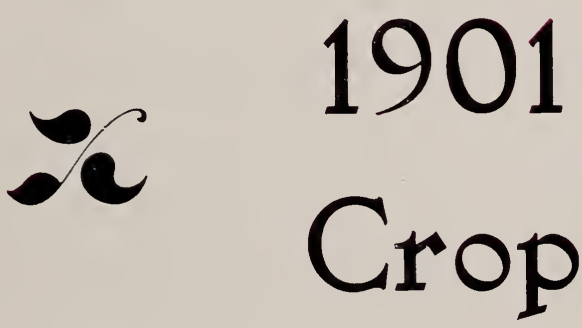

Pure Stock,

Systematic Methods.

Extreme Care.

Personal Attention.

W, H, BARRETT, Adrian, Mich. 
J Y y PLANs for the coming year in$\therefore$ clude the growing of the following varieties of Tomato Seeds :

\section{Atlantic Prize,}

Acme,

Beauty,

Stone,

Perfection,

Paragon,

Favorite,

Royal Red,

Selected Trophy,

and also a limited quantity of Boston Marrow Squash.

I started in this business nine years ago.

I had previous experience in seed growing and thought there was room for an exclusive Tomato seed grower to build up a large business if certain theories of mine were followed.

I used the best stocks only. 
The work was so arranged that there could be no careless mixture.

The buyer received exactly what he ordered-no substitution.

Systematic and economical methods have improved the quality and at the same time lowered the price.

The results have been, a constantly increasing trade and well satisfied customers.

I select and improve the strain of the sorts grown but I make no effort to bring out or experiment with new varieties.

I grow large quantities of a few kinds and select those which are in the greatest demand, and add to the number of sorts from year to year as rapidly as the facilities can be secured and help trained for the work.

Each variety is grown in a locality by itself, with no other kinds in that vicinity, and from seeds and plants furnished by me.

The fields are inspected and rogued. 


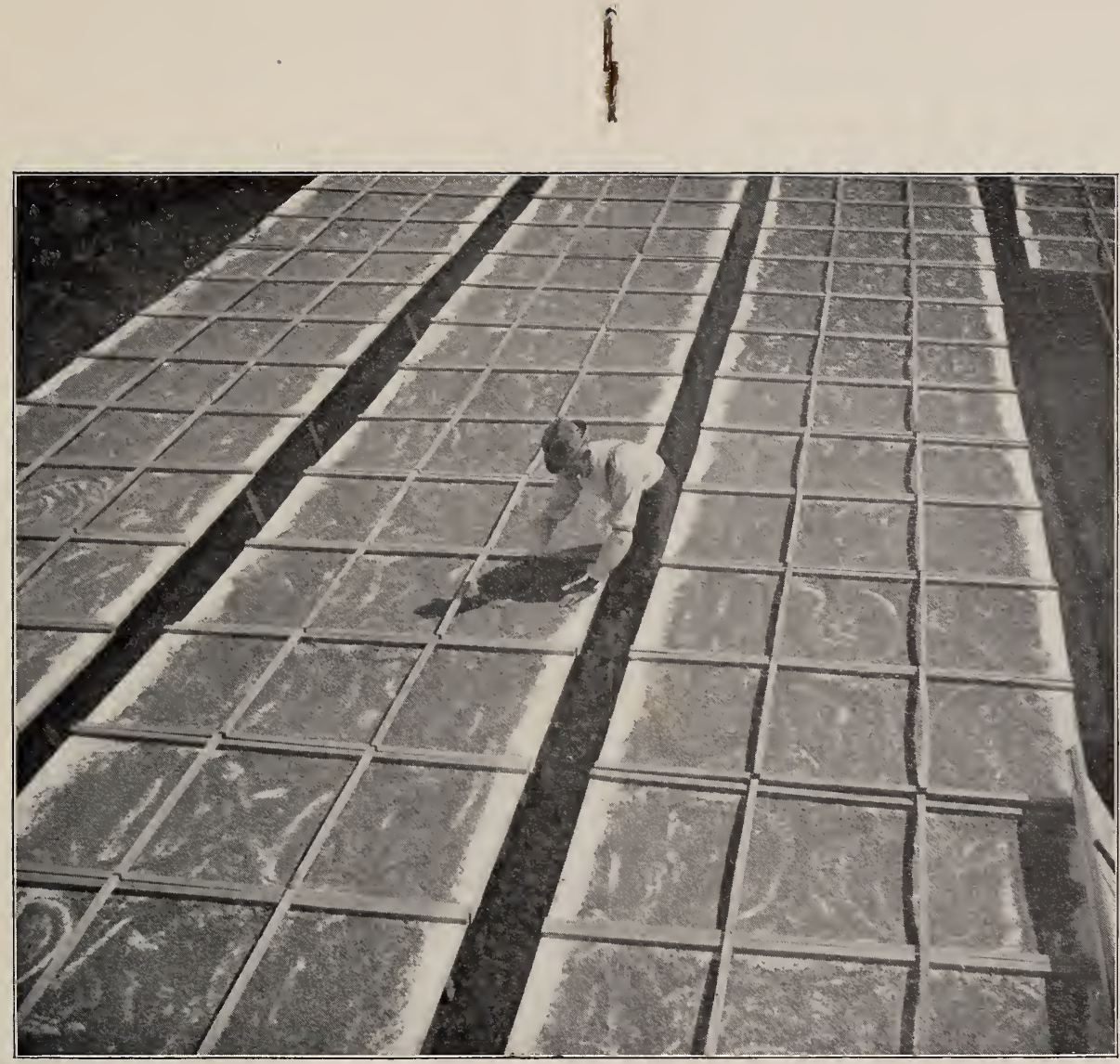

CURING FAVORITES.

1 
The ripe Tomatoes of each variety are then hauled to a central and convenient point for that sort, where they are carefully inspected and all the seeding, curing, cleaning and bagging done by my own experienced men, who have nothing to do with any sort other than their own.

The tools, machines, and drying frames used are all separate and distinct for each sort.

Do you know of any hetter way to guard against careless mixture?

How does this system compare with that of the grower who has a half dozen or more kinds on the same farm and often in the same field and does all the work with the same men and one set of tools?

In a few cases, to accommodate a customer, I have taken an order for some sort not on $\mathrm{my}$ list and had the lot grown by a near by farmer on contract.

The results have been very disappointing and I must decline to grow any outside sorts. 
With the grower of a small "Patch" of Tomatoes, who washes the seed in a muddy stream or beside a wind pump, the tendency is to pick the ground clean-the small, green and frozen fruits. We leave these. It does not pay. The vitality of such seeds is very poor and they produce late vines and inferior fruit.

On account of not picking these fruits and owing to improved methods of curing, my seeds always test exceptionally high.

I have never had a claim on account of low test of any seed grown by me.

There may be other Tomato Seeds as good but there can be none better than mine.

I am also prepared to grow a limited quantity of Boston Marrow Squash from my own choice strain of stock which has been selected by me personally for fiftecn years. The fruits are of good size, deep orange color mottled with cream, the flesh fine grained and thick.

In asking for prices for growing please give an estimate of your probable needs of the different sorts. 


\section{CROP.}

Atlantic Prize,

Acme,

Beauty,

Stone,

Perfection,

Paragon,

Favorite,

Royal Red,

Selected Trophy.

$\therefore$

W. H. BARRETT,

Adrian, Mich. 



\section{Gigh Grade}

Comato

seeds

900009090

I90I

Crop

W. H. BARRETT,

ADRIAN, MICH. 